\title{
SocArXiv
}

Preprint : March 11, 2021

10.31235/osf.io/2xuqf

\section{Do generous unemployment benefits facilitate transition into more-secure labour market positions? Insights from a multilevel latent Markov model}

\author{
Adeline Otto* \\ Centre for Sociological Research \\ KU Leuven
}

\author{
Martin Lukac* \\ Department of Methodology \\ London School of Economics \\ and Political Science
}

\begin{abstract}
A large body of research suggests that generous welfare provisions for jobseekers create a disincentive to work. Other scholars argue that generous benefits can reduce unemployment by serving as a job-search subsidy. One caveat in this literature is that, when testing the two hypotheses, many scholars conceive of labour markets as homogeneous entities or they theoretically assume a certain insider/outsider divide. In this article, we claim that the employment effect of generous benefits varies between labour market segments. Analysing EU-SILC panel data of 27 European countries, we find that more-generous unemployment cash benefits enhance the transition from unemployment into more-secure work while discouraging transition into less-secure work in terms of temporal, economic and organisational security. Contrary to existing research, welfare generosity is measured by aggregated information on individual benefit receipt. Labour market segments are identified by latent class analysis and transitions between segments are estimated by Multilevel Latent Markov Models.
\end{abstract}

Keywords: unemployment, segmentation, welfare state, labour economics, transition cost economics.

Current version: https://osf.io/preprints/socarxiv/2xuqf

* Both authors contributed equally. 


\section{Introduction}

Many scholars have argued that generous social benefits for jobseekers generate a disincentive to work or prolong unemployment (Card et al., 2015; Lalive, 2007; Meyer, 1990). By contrast, other scholars suggest that generous benefits can positively affect overall employment levels by serving as a job-search subsidy (Gangl, 2004, 2006; Pollmann-Schult \& Büchel, 2005 ) or as a financial resource (Lehwess-Litzmann \& Nicaise, 2020) to wait and prepare for more-adequate job offers. With inconclusive results, both hypotheses have been tested in a multitude of micro-level case studies and macro comparative analyses. However, what appears to be underestimated in this literature is the social division of labour markets and that employment effects of social benefits might differ for various labour market segments.

Labour market segments can be understood as social divisions of labour markets in terms of wages, working conditions, and chances of advancement (Lukac et al., 2019). According to Emmenegger et al. (2012) as well as Clasen and Clegg (2011), labour markets have witnessed growing inequality and dualisation because individuals' social rights increasingly depend on their labour market status. Social protection is found to be concentrated in segments with secure employment, while individuals with unstable, precarious or insecure employment often lack or have insufficient access to social benefits. Ongoing institutional changes seem to reinforce these social divides (Hassel, 2001; Palier \& Thelen, 2010), making it harder for people in insecure or precarious employment to escape instability. Although a wide range of research on employment and social policy acknowledges the complex and dynamic nature of labour market segmentation (see the literature review of Davidsson and Naczyk, 2009) and recognises the importance of studying post-unemployment trajectories (Gangl, 2004; Lalive, 2007; Pollmann-Schult \& Büchel, 2005; Portugal \& Addison, 2008), few studies (Biegert, 2014) have empirically studied cross-national transition patterns from unemployment into a divided labour market or how such transitions depend on the generosity of unemployment benefits in a country.

Against this background, using EU-SILC panel data of 27 European countries collected between 2011 and 2014, we investigate: (1.) What are transition probabilities from unemployment into a particular labour market segment and how do transition probabilities compare across countries? (2.) Do transition probabilities depend on the generosity of unemployment benefits? (3.) Do cash benefits alone help the transition into specific labour market segments or does this also depend on other welfare programmes such as active labour market policies (ALMP)?

The article adds to existing knowledge about employment effects of unemployment benefits in several ways: Theoretically, it goes beyond studying how benefits influence the transition from unemployment into employment or into a particular contract type, income and skills group, which are frequently assigned a theory-driven labour market insider or outsider status. Instead, we follow earlier research (Lukac et al., 2019) measuring labour market segments with latent class cluster analysis. This means we study individuals' transition probability from unemployment into empirically modelled labour market segments and whether higher unemployment cash benefits help move into more-secure work. Methodologically, the article embraces two innovations. First, to identify labour market segments and transitions between segments, we extend the earlier-mentioned latent variable approach of measuring labour market segmentation to longitudinal data by using a multilevel latent Markov model (MLMM). Second, in following recent social indicator research (De Deken \& Clasen, 2013; Otto, 2018; 
van Oorschot, 2013), we use aggregated micro-level information on relative benefit amounts to approximate national variation in welfare 'generosity' in contrast to the prevailing use of social expenditure or social rights data. The advantage of this proxy is that it reflects more directly the extent of public welfare provision in terms of higher benefit amounts than overall expenditure figures or case-based benefit rights indexes.

The remainder of the article is structured as follows: In the next two sections, we elaborate in a short literature review on the theoretical background of this paper and demonstrate the relevance of our research questions. After this, we describe the data we use and namely how we operationalise and measure transition between labour market segments as our dependent variable and the generosity of public welfare provision - here unemployment benefits - as our key independent variable. This is followed by the methods section, before we present and discuss our results.

\section{Literature review}

\subsection{State of the art: the employment effect of social cash benefits}

Contemporary scholarship is divided with regard to the employment effect of generous social cash benefits, whereby 'generosity' often either refers to high benefit amounts, a long duration for which benefits are paid or a broad accessibility of benefits in terms of population coverage, entitlement and/or eligibility criteria. At least two different perspectives can be distinguished. One conceives of individuals as economic actors (McCall, 1970; Mortensen, 2001) whose decision to accept a certain job depends on their reservation wage and who trade off the costs of employment against the benefits of welfare programmes. From this perspective, personal preference, responsibility and effort explain individuals' employment status and work intensity. Following these reflections and depending on the outcome variable chosen, generous social benefits are believed to disincentivise (rapid) re-employment or more-intensive levels of employment as they increase the reservation wage. This work-disincentive hypothesis has been confirmed by various quantitative studies, with many micro-level studies looking at benefit policies and how they affect unemployment duration or the transition rate from unemployment into employment (e.g. Barbanchon, 2016; Bernardi, 2001; Card et al., 2015; Lalive, 2007; Meyer, 1990; Portugal \& Addison, 2008; Uusitalo \& Verho, 2010) and with several macrolevel comparative studies relating national unemployment rates to certain benefit policies and labour market institutions (Bassanini \& Duval, 2006; Layard et al., 2005; Nickell, 1997). Critics of these welfare-sceptical research findings stress that the size of the effects are typically quite modest or even very small (Atkinson \& Micklewright, 1991; Howell \& Rehm, 2009; Lehwess-Litzmann \& Nicaise, 2020; Sjöberg, 2000), that single-country studies cannot account for macro-economic aspects and that cross-country macro-comparisons often suffer from poor compatibility of chosen indicators (Biegert, 2017).

The other perspective suggests that generous social cash benefits can reduce unemployment by serving either as a subsidy to invest in skills or as a financial resource to eventually improve the job match in terms of wages, occupation, or job security (Gangl, 2004, 2006; PollmannSchult \& Büchel, 2005). Assumptions behind the job-search subsidy (Burdett, 1979) and the welfare-resource hypothesis (Lehwess-Litzmann \& Nicaise, 2020) are, on the one hand, that individuals strive to work as an important aspect of societal participation and/or fear 
the stigmatising and scaring effect of long-term unemployment (Gangl, 2004, 2006; Nilsen \& Reiso, 2011). On the other hand, employment is believed to be the result of a matching process between labour supply and labour demand, and in this process generous benefits can strengthen workers' bargaining power and work as a financial buffer and enabler for better job matches and higher employment levels in the long run and at global level (Acemoglu, 2001; Wulfgramm \& Fervers, 2015). Various micro- and macro-level studies support this welfare-positive perspective. On the micro-level, scholars found, for example, positive effects on the quality of skill or income related job matches after periods of unemployment (Addison \& Blackburn, 2000; Gangl, 2004; Pollmann-Schult \& Büchel, 2005). From macro-level comparisons it appears that post-unemployment stability is particularly pronounced in countries with more-generous unemployment benefits (Tatsiramos, 2009) and that generous initial unemployment benefits promote employment levels as well as job quality (Nelson \& Stephens, 2012). Similar to this, Gangl (2006) showed that more-generous unemployment benefits mitigate the risk of earnings losses in post-unemployment because they seem to allow jobseekers to look for adequate jobs in terms of income, contract and skills match. However, the latter study also shows that this mechanism works particularly well in countries with relatively flexible labour markets.

Gangl's finding inspired other research investigating the influence of labour market institutions on the employment effect of generous social benefits. For example, Biegert (2017) proposes that higher unemployment benefits only reduce unemployment in labour markets with a moderate institution-driven insider/outsider divide, that is with a weak employment protection legislation, low degrees of unionisation and a system of fragmented wage bargaining. The author suggests that this is possibly because only where there are few institutionalised advantages for insiders, and hence small employment barriers for outsiders, higher benefits can effectively reduce unemployment.

The brief literature review demonstrates the importance of social divides in labour markets and the key role of institutional interdependencies. However, a serious caveat in existing research is that most scholars assume a homogeneous labour market. It is currently underinvestigated in how far social benefits - and namely unemployment cash benefits - might not only operate differently in specific labour market contexts but also for different segments of the labour market. The questions that arise are: (1.) What are the transition probabilities from unemployment into particular labour market segments in Europe and how do transition probabilities compare across countries? and (2.) How does the generosity of unemployment benefits influence transition probabilities into particular labour market segments? In other words, are generous benefits more valuable for transition into particular positions. Finally, bearing in mind social investment theory (Bonoli \& Natali, 2012; Morel et al., 2012), we also inquire (3.) whether cash benefits alone help the transition into specific labour market segments or if this depends on other welfare programmes, namely active labour market policies. Before formulating research hypotheses, the following section will give a more detailed overview of what is meant by labour market segmentation, how it can be operationalised and measured, and how it relates to the discussion about the employment effect of generous social benefits.

\subsection{Labour market segmentation: theory and measurement}

The institutional division of labour markets into segments with different characteristics is 
one result of ongoing global changes and a growing challenge for social cohesion in developed welfare democracies. The ensuing concept of labour market segmentation can be linked to the dual labour market theory (Doeringer \& Piore, 1971; Goldthorpe, 1984; Kalleberg, 2003) whereby the primary labour market offers "relatively high wages, good working conditions, chances of advancement, [...] and above all, employment stability" (Piore, 1972, p. 126). By contrast, the secondary labour market is marked by unrestrained market mechanisms of supply and demand and characterised by low-paid (service) jobs, fixed-term employment, part-time work, poorer conditions, and low employment stability. This institutional 'logic of dualisation' is maintaining traditional protection for insiders where possible, while accepting a subordinate status of the growing number of outsiders (Palier \& Thelen, 2010).

Beyond these direct labour market-related disadvantages, outsiderness is also found to stretch to spheres of social protection (Davidsson \& Naczyk, 2009). For example, social protection systems may discriminate workers by employment contract or continuity (Grimshaw et al., 2018). Some workers may have to rely on in-work benefits, either because they do not qualify for social insurance schemes (Leisering \& Leibfried, 1999; Paugam, 1995) or because their labour income or their working intensity is too low to make ends meet (Bruckmeier et al., 2013; Horemans, 2017). Further, social protection inequalities between insiders and outsiders may arise as a consequence of inaccessible occupational pension and health insurance schemes (Kalleberg et al., 2000).

Recent research (Davidsson \& Naczyk, 2009) claims that labour market segmentation often relies on predefined characteristics of segmentation (e.g. temporary employment is often associated with a disadvantaged position in the secondary segment) and that studying insiders and outsiders ignores the plurality of segmentation as well as within-group variation (FernándezMacías, 2012). Thus, a multidimensional approach to labour market segmentation is needed: one which mirrors the complexity of measurement while guaranteeing cross-national comparability. Building on institutional segmentation theory (Beynon et al., 2002; Rubery, 1978) which suggests that labour market divides result from variation in the extent to which employment conditions are regulated around decent standards and embedded in comprehensive employment practices, Doerflinger et al. (2019) argue that insecurity is a convenient concept to distinguish various labour market segments because it causes major dividing lines in contemporary labour markets. Using Rodgers' (1989) framing of insecurity, the authors propose to operationalise labour market segmentation by temporal, organisational, economic and social insecurity. Based on this research, Lukac et al. (2019) empirically modelled labour market segments and found three distinct groups across European countries: the group of the standard employees, the group of managerial employees and the group of disadvantaged employees. These segments differ with regard to their working hours, contract type, the number of non-standard working hours, their supervisory responsibility and their income.

For our research, we draw on this idea of insecurity-divided labour markets and on Gangl (2006). The latter acknowledged that unemployment benefits may reinforce patterns of labour market segmentation when their partly decommodifying function facilitates workers to stay within their pre-unemployment occupation and industry. At the same time, he also found that unemployment benefits may weaken labour market boundaries where they enable workers to move into more-advantageous segments. Following these reflections, it can be broadly hypothesised that unemployment benefits influence transition into different labour market segments. Further, in line with the job-search subsidy and welfare-resource theory, we could expect that in contexts with more-generous benefits the probability of transition into more- 
secure jobs is higher than in contexts with relatively low benefits. In generous contexts, benefits could serve as a financial buffer allowing jobseekers to either be more selective about job offers or to invest in specific skills development. This ultimately increases the quality of the match between the jobseeker and the job, thus boosting overall employment levels.

Nevertheless, as was mentioned earlier, labour market policies and institutions can also be expected to influence the relationship between generous welfare provisions and labour market participation. More specifically, so-called new welfare or social investment policies aim to mobilise more people into paid work, improving human capital and ensuring fairer access to opportunities (Taylor-Gooby et al., 2014). Active labour market policies and namely investment in training opportunities form an important part of enabling activation strategies. Against this background, we hypothesise that generous unemployment benefits are particularly helpful for the transition into more-secure work where they are combined with high levels of training-related ALMP spending.

\section{Data}

To test our hypothesis and to answer our research questions, we need comparable crossnational and longitudinal data on individuals' cash benefit income and labour market characteristics as it is offered by the European Union Statistics on Income and Living Conditions (EU-SILC) data. More specifically, we use panel data from 2014, 2013, and 2012 (the version released in October 2017), which contains individual- and household-level observations for 30 European countries, of which we selected $27^{1}$. We choose the three panels as they mostly refer to the years after the 2008/2009 recession, as this is the data we had available at the start of this research and because pooling three panels maximises our number of observations per individual.

The EU-SILC has a rotating panel structure and most countries keep households in the sample for a maximum of four years. For the three panels we use, this means the data covers the survey years 2009 to 2014. To avoid duplications when pooling the panels, we use information on the time for which individuals were first interviewed ${ }^{2}$ and attribute new, unique household and personal identifiers. From the panel, we keep only individuals aged 16 to 64 years as we are interested in the relationship between unemployment benefit generosity and labour market participation. Further, we limit our sample to individuals who were either unemployed or in dependent employment, therefore excluding self-employed, students (or in unpaid work experience), permanently disabled or those unfit to work, individuals in compulsory military service and those fulfilling domestic tasks or care responsibilities. To model the labour market segments and transition probabilities we use the full selected data sample but limit it to individuals with at least two out of four available observations. These observations are not necessarily consecutive. To balance the panel, we include missing observations as additional rows containing missing values on the various response variables. Before explaining the method used, the following section will elaborate on the operationalisation and measurement

\footnotetext{
${ }^{1}$ Austria (AT), Belgium (BE), Cyprus (CY), Czech Republic (CZ), Denmark (DK), Estonia (EE), Spain (ES), Finland (FI), France (FR), Greece (GR), Hungary (HU), Ireland (IE), Iceland (IS), Italy (IT), Lithuania (LT), Luxembourg (LU), Latvia (LV), Malta (MT), the Netherlands (NL), Norway (NO), Poland (PL), Portugal (PT), Romania (RO), Sweden (SE), Slovenia (SI), Slovakia (SK), United Kingdom (UK). The country choice is based on the precautious exclusion of Bulgaria where the data on unemployment benefit receipt had strong and incomprehensible year-to-year variations.

${ }^{2}$ Variable DB110, value "9"
} 
of the dependent and independent variable(s) used this study.

\subsection{Operationalisation of the dependent variable}

Our dependent variable is the transition between different labour market segments. It is extracted directly from the model, which will be explained below. In addition to unemployment, the measurement of labour market segmentation is based on four dimensions of insecurity - namely temporal, organisational, economic, and social security (Rodgers, 1989).

Temporal insecurity refers to aspects related to continuity of employment, such as the type of contract a worker holds. Permanent contracts are regarded as offering more security to the worker than a temporary contract. Additionally, temporal insecurity distinguishes between full-time and part-time work. Full-time employment is generally considered more secure than part-time employment, especially where part-time work might be involuntary (due to inability to obtain full-time employment) or fluctuates in accordance with demand. Although this distinction is useful in evaluating which social groups suffer from volatile and precarious employment, we refrain from applying this distinction, as for our classification the voluntary or involuntary character of part-time work does not change the fact that this type of employment is less secure than full-time employment - regardless of the family situation or any other considerations. Non-standard working hours is the third aspect related to temporal insecurity. They are an approximation of variability of working hours and hence possible income insecurity where they involve unpredictable shift, casual or on-call work or zero hour contract work. Short hours are operationalised as lower than 38 hours per week, standard hours as 38-40 hours per week, and long hours as more than 40 hours of work per week.

Organisational insecurity is measured by a degree of control a worker has over work processes. Lack of control is presumed to indicate more insecurity than being in control (Sverke et al., 2006). Organisational insecurity is inherently linked to company hierarchies, as higher positions often come with more control. Based on these considerations, we use managerial status of the worker as a proxy for measuring organisational insecurity.

Economic insecurity is approximated by wages. Low wage levels correspond to higher levels of insecurity as they can be linked to struggles to make ends meet or increased probability of experiencing income poverty. The wage variable is constructed as categorised variant of the original continuous variable into four equally sized quartiles with country-specific cut-offs.

We are aware that social insecurity represents another important dimension, namely a lack of protection against dismissals and discrimination or of income-replacing welfare provision. Nevertheless, unlike temporal, organisational and economic insecurity, it is a macroinstitutional and legal feature of a country and therefore we did not include it in the measurement of labour market insecurity. Rather, we use it as an explanatory independent variable that distinguishes the rate of transitions between segments. Its operationalisation follows below.

Altogether, the presented operationalisation aims to reflect the latent and multidimensional nature of labour market segmentation (Lukac et al., 2019; Yoon \& Chung, 2015). Our approach focuses mainly on objective indicators of insecurity. Although we acknowledge the importance of considering also the subjective side of insecurity -i.e. workers' perceptions, experiences, and expectations (Chung \& Mau, 2014; Green, 2009; Greenhalgh \& Rosenblatt, 1984) - it lies beyond the scope of our paper. 
In addition to measuring labour market segments via the four insecurity dimensions, we add the unemployed as another segment of the labour market. Modelling the unemployed from the insecurity criteria is not possible as this group does not record information on the indicators of insecurity (contract type for example). Instead, we determine the unemployed by the self-defined socio-economic status, which is added as another category to all the indicators of insecurity. This approach allows us to model the observed category of unemployed along with the unobserved labour market segments and to estimate transitions between these categories. We are aware that unemployed people can take up certain amounts of work and are increasingly encouraged to do so to stay eligible for benefits (Eichhorst et al., 2008; Knotz, 2018; Langenbucher, 2015). Nevertheless, the reason for refraining from including such cases is that they would only load on our wage indicator but not on all the other indicators.

\subsection{Operationalisation of the independent variables}

Scholars have suggested many ways to operationalise the extent of public welfare provisionsometimes also referred to as welfare generosity or welfare effort - as a dependent or independent variable (Kunißen, 2018). Given that we are interested in how contexts with moregenerous benefit amounts influence individuals' job-search and ultimately their transition into a specific labour market segment, we use individual-level, survey-based benefit receipt information as a hitherto underused indicator of the extent of public welfare provision (De Deken \& Clasen, 2011, 2013; van Oorschot, 2013). We prefer this welfare generosity indicator over social benefit expenditure data as a global cost-side measure that cannot distinguish between benefit access and benefit amounts. We also prefer it over social benefit rights data as policyintended entitlement-side approximation of the extent of public welfare provision, which only reflects replacement rates for ideal-type cases ${ }^{3}$.

For the purpose of this research, we use EU-SILC cross-sectional information on unemployment benefit income and operationalise benefit receipt, and more specifically benefit amounts, as suggested by van Oorschot (2013). Thus, in the first step, individual-level unemployment benefit amounts are measured as the proportion that an individual's benefit income takes relative to the median total household income in a country's working age population. The measurement indicates the relative amount of a benefit received by a person compared with the level of income that is a minimum for half of the national working population. At the national level, relative unemployment benefit amount rates (UEBA) are calculated as the median of the individual-level benefit amount rate. All unemployment benefit income is gross income. Admittedly, this is suboptimal but unfortunately the EU-SILC does not provide net benefit amounts for all countries. The use of a relative measurement is preferred to ensure comparability across countries with different levels of economic development and purchasing power.

Further, to investigate whether the effect of unemployment benefit generosity on the transition into particular labour market segments depends on labour market policies, we include an

\footnotetext{
${ }^{3}$ For example, ideal-typical OECD-based gross and net income replacement rates are built on pre- or posttax benefits defined for a 40-year-old worker with continuous employment since age 18. The replacement rates are for the first month of unemployment and calculated at two thirds of the average production worker level of earnings for different household types. Such rates risk to ignore income ceilings in benefits and they can hide decreasing relative benefit amounts either because of a non-adaptation of benefits to median total household incomes (Otto \& van Oorschot, 2018) or because the indicator assumes constant replacement rates throughout a year.
} 
interaction term in our model. Since, we expect that transitions into secure positions could especially be helped by means of training, we include Eurostat figures on ALMP spending in the form of training ${ }^{4}$.

\subsection{Covariates}

We use a set of individual-level covariates in later stages of the analysis to investigate the socio-demographic composition of the extracted labour market segments. Gender is included, as some labour market segments are likely to be gender imbalanced. More specifically, based on existing research (e.g. Fourage \& Muffels, 2008; International Labour Organisation, 2017), women are expected to more frequently occupy insecure segments than men. Similarly, since education is often claimed to be a strong predictor of labour market success, we examine the distribution of attained education (ISCED) coded as low (pre-primary and primary education), medium (lower and upper secondary education), and high (post-secondary and tertiary education). Finally, we inspect the age across the extracted segments, as vulnerable labour market groups such as the youth or pre-retirement workers might concentrate in particularly insecure labour market segments.

Although we use random effects to account for country-level unobserved heterogeneity, we estimate additional models including GDP per capita (at current prices in Purchasing Power Standards ${ }^{5}$ ) as sensitivity analysis to ensure that our results are not driven by unaccounted spurious correlations. The reason for controlling for GDP per capita is that transition probabilities might depend on the economic situation as an indicator for available positions to transfer to.

\section{Methodology}

To model labour market segmentation in time and across space, we use a multilevel latent Markov model (MLMM). A latent Markov model (Langeheine \& van de Pol, 1990) — often also referred to as hidden Markov model (Baum et al., 1970; MacDonald \& Zucchini, 1997) or latent transition model (Collins \& Lanza, 2010) - is a mixture model with a dynamic categorical latent variable called latent state. The model assumes that the observed data originates from an unobserved process evolving over time according to a first-order discretetime Markov chain with a finite number of latent states (Collins \& Lanza, 2010; Vermunt, 2010a). This unobserved process is the latent attribute of interest - in our case, transitions between labour market segments (segments are considered latent states). We use a multilevel extension (Vermunt, 2010a) to model the nested structure of lower-level units (individuals) within higher-level units (countries) and to account for unobserved heterogeneity across countries. Unlike the multi-group approach (with dummy variables), incorporation of a parametric random effect allows us to model the effect of a country-level time-varying predictor (benefit amount rate) on the transition structure.

The MLMM is a useful method for longitudinal research as it accounts for unobserved heterogeneity, autocorrelation, and measurement error (Vermunt et al., 2008). Unobserved heterogeneity is captured by a time-constant latent variable akin to a parametric random effects model. Autocorrelations are taken care of by the first-order Markov process, where the la-

\footnotetext{
${ }^{4}$ Eurostat tag: LMP_EXPSUMM

${ }^{5}$ Eurostat tag: nama_10_pc
} 
tent state of an individual at time $t$ depends on the latent state in the previous observed time-point $t-1$. Finally, measurement error or misclassification is accounted for by allowing for an imperfect relationship between the time-specific latent states and their observed responses. Moreover, the commonly occurring problem with missing data in panels is readily accommodated by the maximum likelihood estimation of the MLMM. The model can deal with missing values on response variables but not on covariates under the assumption that the missing data are missing at random (Vermunt et al., 2008).

The model selection is performed in a sequential manner by gradually increasing the number of latent states in the model. The desired number of latent states is always a source of controversy with latent class modelling. To decide on the final number of latent states, we run a model only including response indicators and country random effects to avoid influencing the model fit by covariates and country-level predictors. Once we arrive at the final number of latent states, the model is re-estimated with covariates and country-level predictors as specified in the section above.

The model fit is conventionally evaluated by either likelihood based indices or information criteria (IC) indices. As the former has several known limitations (see Hagenaars \& McCutcheon, 2002), we rely on the latter. More specifically, we use the Bayesian information criterion (BIC) and sample-size adjusted BIC (SABIC). According to a simulation study by Nylund et al. (2007), BIC and SABIC were the most successful indices at identifying the correct number of latent classes with larger sample sizes and thus they also guide the model selection in our analysis. Overall, the lower the value of BIC and SABIC, the better the model fits the data.

\section{Results}

\subsection{Model selection}

We aim to choose a model that is the best trade-off between model fit and parsimony. However, as we work with a very large sample, it is likely that even the BIC and SABIC will not indicate a final number of states but suggest including additional states (which will eventually result in extracting small clusters that are of very little use). Our strategy is to look for a number of states that provides the most comprehensible picture of labour market segmentation and clearly interpretable latent states with respect to the proposed theory. Hence, we look for a number of latent states where the additional information from adding another latent state is substantially diminished to previous additions. We consequently inspect the latent state profiles for interpretability over the best model candidates. Keeping model parsimony in mind, when the addition of another latent state brings only a minor improvement of the model fit (BIC and SABIC) or extract a latent state with a very low prevalence, we opt for the simpler model.

We estimated models up to six latent states, with model fit indices shown in Table 1. As expected, the largest drops in BIC and SABIC occur with adding first latent states. After four latent states, the reduction in BIC and SABIC becomes, however, much smaller than with previous additions. Adding the fifth latent state splits the less-secure labour market segment into part-timers and temporary workers. This split is substantially interesting from a theoretical point of view and therefore justifiable. Model fit improvement by adding a 


\begin{tabular}{lcccc} 
& Npar & LL & BIC(LL) & SABIC(LL) \\
\hline \hline 1 latent state & 26 & -3387102 & 6774555 & 6774472 \\
2 latent states & 45 & -2557202 & 5115011 & 5114868 \\
3 latent states & 68 & -2308007 & 4616930 & 4616714 \\
4 latent states & 95 & -2141713 & 4284705 & 4284403 \\
5 latent states & 126 & -2059669 & 4121036 & 4120635 \\
6 latent states & 161 & -2019963 & 4042094 & 4041582 \\
\hline
\end{tabular}

Table 1: Model selection

sixth latent state seems to be relatively small in comparison to previous states and leads to extraction of a relatively small latent state cluster, which is of no substantial meaning. As a result, we proceed with our analysis with the solution containing five latent states.

\subsection{Segmentation profiles}

When inspecting the estimated segmentation profiles (Table 2), we identify four groups in addition to the unemployed. Based on the different characteristics, we labelled these groups as part-time work, temporary, standard, and managerial.

The group of temporary workers is the largest group, covering on average $26 \%$ of all individuals in the sample population. The smallest group is the group of unemployed, representing eight per cent. For reasons of convenience, we describe these different groups by starting with managers as the group with the highest level of security. When compared to the other labour market segments, individuals in this group tend to work full-time, hold permanent contracts, yet they record more often high non-standard working hours than the other groups. Relatively speaking, they also indicate more often a supervisory responsibility and have higher wages. Altogether, individuals who populate this labour market segment benefit from high levels of temporal, organisational, and economic security.

Standard employment is also characterised by high shares of individuals working full-time and holding permanent contracts. Contrary to the previous group, they work more often standard working hours and most of them do not have any supervisory responsibility. Their income from wages is medium to high. Generally, this means that individuals in the standard employment labour market segment enjoy a high level of security that is only curtailed by a lack of control of the work processes. This again often means less control over working conditions, wages and the pace of work.

The group labelled as the segment of temporary workers also almost exclusively records fulltime employment. However, individuals in this labour market segment have much higher incidence of temporary work than individuals in the previous two segments. They have medium amounts of non-standard working hours, medium to low wages, and rarely hold supervisory competences. By contrast, individuals in the fourth labour market segment that we could identify are marked by working nearly exclusively part-time, with higher incidences of temporary work as compared to the managerial and standard labour market segment, with low non-standard working hours, low wages and hardly any supervisory responsibility. Due to these characteristics, we labelled this group the part-time work segment.

In terms of the social configurations of our segments (Table 3), we find that the unemployed in our sample are often having low to medium educational levels, tend to be male, and are on average 47.33 years old. Part-timers are slightly higher educated, with $22 \%$ of some of them 


\begin{tabular}{|c|c|c|c|c|c|}
\hline & Unempl. & Part-time & Temp. & Stand. & Manager. \\
\hline Size & 0.08 & 0.21 & 0.26 & 0.23 & 0.22 \\
\hline \multicolumn{6}{|l|}{ Working hours } \\
\hline Full-time & 0.00 & 0.05 & 0.99 & 0.99 & 0.99 \\
\hline Part-time & 0.00 & 0.95 & 0.01 & 0.01 & 0.01 \\
\hline Unemployed & 1.00 & 0.00 & 0.00 & 0.00 & 0.00 \\
\hline \multicolumn{6}{|l|}{ Contract type } \\
\hline Permanent & 0.00 & 0.76 & 0.76 & 0.95 & 0.97 \\
\hline Temporary & 0.00 & 0.24 & 0.24 & 0.05 & 0.03 \\
\hline Unemployed & 1.00 & 0.00 & 0.00 & 0.00 & 0.00 \\
\hline \multicolumn{6}{|l|}{ Non-stand. working hours } \\
\hline Low & 0.00 & 1.00 & 0.28 & 0.30 & 0.27 \\
\hline Medium & 0.00 & 0.00 & 0.56 & 0.54 & 0.44 \\
\hline High & 0.00 & 0.00 & 0.16 & 0.16 & 0.29 \\
\hline Unemployed & 1.00 & 0.00 & 0.00 & 0.00 & 0.00 \\
\hline \multicolumn{6}{|l|}{ Supervisory responsibility } \\
\hline No & 0.00 & 0.98 & 0.98 & 0.96 & 0.83 \\
\hline Yes & 0.00 & 0.02 & 0.02 & 0.04 & 0.17 \\
\hline Unemployed & 1.00 & 0.00 & 0.00 & 0.00 & 0.00 \\
\hline \multicolumn{6}{|l|}{ Income } \\
\hline Low & 0.00 & 0.54 & 0.34 & 0.00 & 0.01 \\
\hline Medium-Low & 0.00 & 0.30 & 0.61 & 0.08 & 0.00 \\
\hline Medium-High & 0.00 & 0.12 & 0.04 & 0.87 & 0.04 \\
\hline High & 0.00 & 0.04 & 0.01 & 0.04 & 0.95 \\
\hline Unemployed & 1.00 & 0.00 & 0.00 & 0.00 & 0.00 \\
\hline
\end{tabular}

Table 2: Latent class profiles

Unempl. Part-time Temp. Stand. Manager.

\begin{tabular}{|c|c|c|c|c|c|c|}
\hline & Size & 0.08 & 0.21 & 0.26 & 0.23 & 0.22 \\
\hline \multicolumn{7}{|c|}{ Education level (ISCED) } \\
\hline & Low & 0.30 & 0.06 & 0.07 & 0.03 & 0.00 \\
\hline & Medium & 0.65 & 0.68 & 0.79 & 0.65 & 0.23 \\
\hline & High & 0.06 & 0.26 & 0.15 & 0.33 & 0.76 \\
\hline \multicolumn{7}{|c|}{ Gender } \\
\hline & Male & 0.58 & 0.03 & 0.46 & 0.62 & 0.67 \\
\hline & Female & 0.42 & 0.97 & 0.54 & 0.38 & 0.33 \\
\hline \multicolumn{7}{|l|}{ Age } \\
\hline
\end{tabular}

Table 3: Socio-demographic characteristics of the extracted labour market segments 


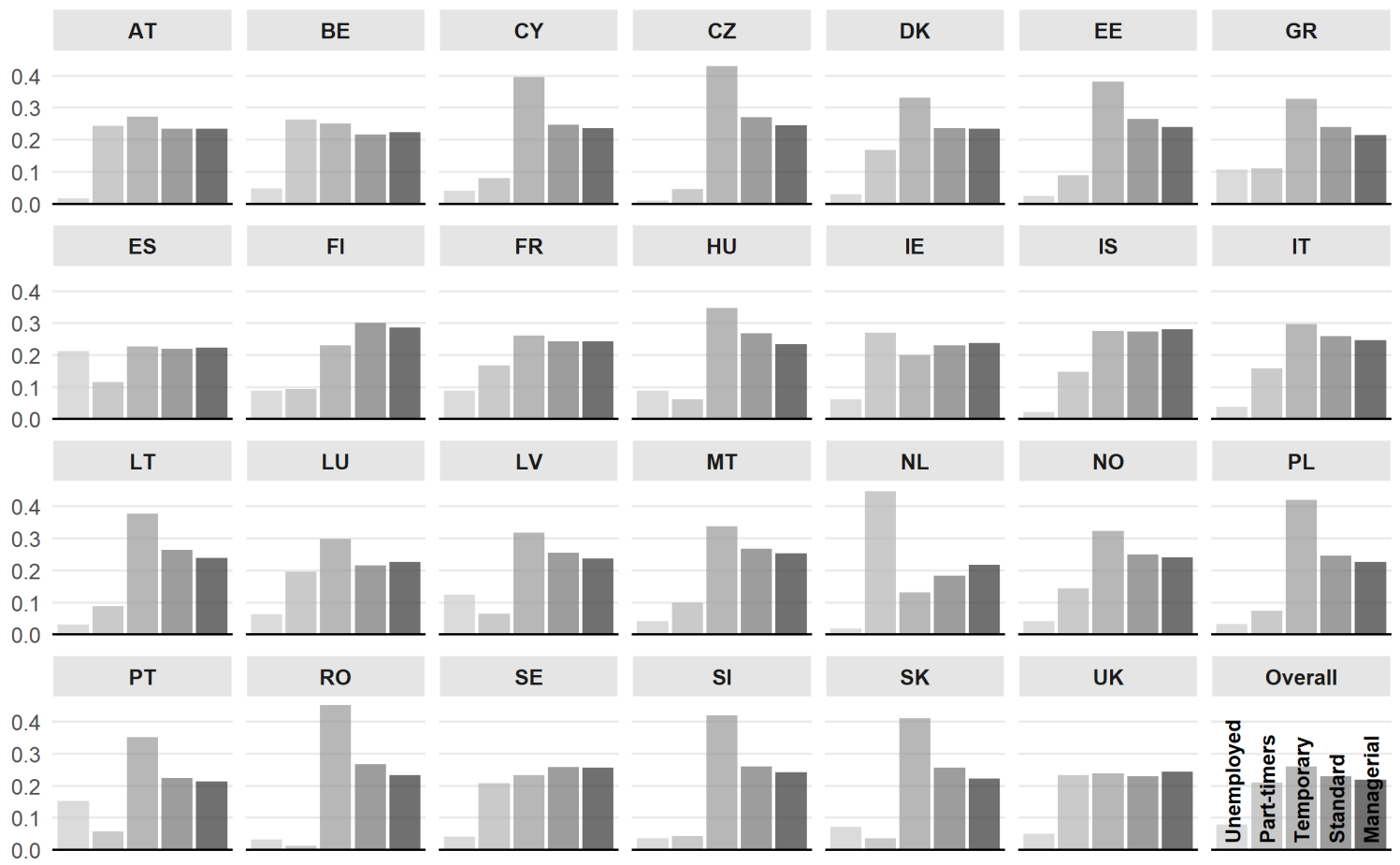

Figure 1: Labour market segment sizes across countries

even being highly educated. Additionally, with a share of $97 \%$, this labour market segment is nearly exclusively populated by women, which is in line with existing research on part-time work being particularly common among women who wish or need to combine employment and care work (Hipp et al., 2015; International Labour Organisation, 2017; Leschke \& Jepsen, 2011). By contrast, temporary work is not marked by a strong gender divide. Instead, individuals in this labour market segment tend to be, on average, younger than in the other identified segments and they have mainly medium levels of education. This could indicate that these jobs are particularly occupied by younger people as first work experiences. For younger people, it might not only be more attractive or less problematic to accept temporary jobs but employers might also be more reluctant of hiring them permanently. Standard employment as well as managerial positions is rather held by men and older workers, with the only difference being the educational level. Whereas standard employment is very much concentrated among individuals with medium to high educational levels, the great majority of individuals in managerial positions are highly educated.

The segments also vary in their sizes across countries (Figure 1). More generally, we find that the division in secure and insecure labour markets is exceptionally strong in many Eastern European countries as well as in Cyprus and Portugal. The part-time work segment is particularly large in the Netherlands.

\subsection{Transition probabilities}

To answer our first research question, we model transition probabilities from unemployment 


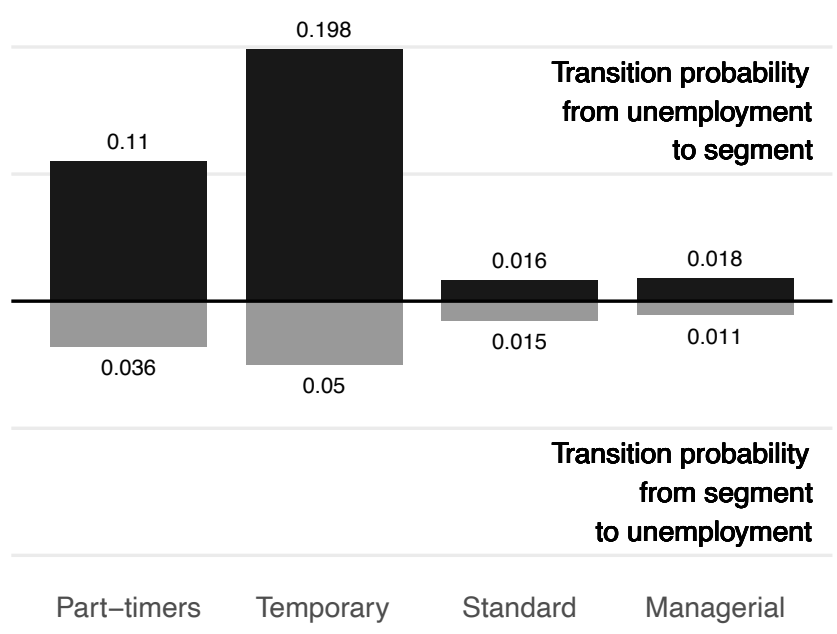

Figure 2: Year-to-year transition probabilities from unemployment to different labour market segments and vice-versa.

into a particular labour market segment and how these probabilities compare across countries. Figure 2 illustrates the transition probabilities from unemployment into any of the labour market segments, and vice versa. As can be seen, for an unemployed individual the probability of moving into the part-time segment is $11 \%$ and $19.8 \%$ for moving into the temporary work segment. Probabilities of making a transition into standard and managerial employment are much lower. Inversely, the probability for an individual in the part-time segment of becoming unemployed is $3.6 \%$ and for an individual in the temporary segment it is $5 \%$. In line with what secure employment suggests, individuals in standard and managerial employment face a much smaller risk of becoming unemployed. By contrast, temporary employees face the biggest risk of becoming unemployed.

Further, because of the negative employment effect of the Great Recession of 2008/2009, we see (Figure 3) that the probability of moving from unemployment into any of the labour market segments generally increases across countries. In many countries, this increase peaks around the year 2012, after which transition probabilities decrease again. In addition to this, probability levels indicate fluctuating and thus rather volatile labour markets in Cyprus, Denmark, Finland, Iceland, the Netherlands, Portugal, and Slovakia.

\subsection{Segment transition}

In our second research question, we want to know whether transition probabilities depend on the generosity of unemployment benefits. To address this question, we include the national relative unemployment benefit amount (UEBA) as a country-level characteristic into our model. To facilitate the interpretation of the results (and given the skewness of our benefit receipt variable), we present predicted values of the transition probability at the $25 \mathrm{th}$, 50th (median), and 75th percentile of the benefit amount.

Following the job-search subsidy and welfare-resource theory, our expectation is that in contexts with more-generous benefits, the probability of transition into jobs that are characterised by relatively high levels of income, temporal and organisational security are higher than in 


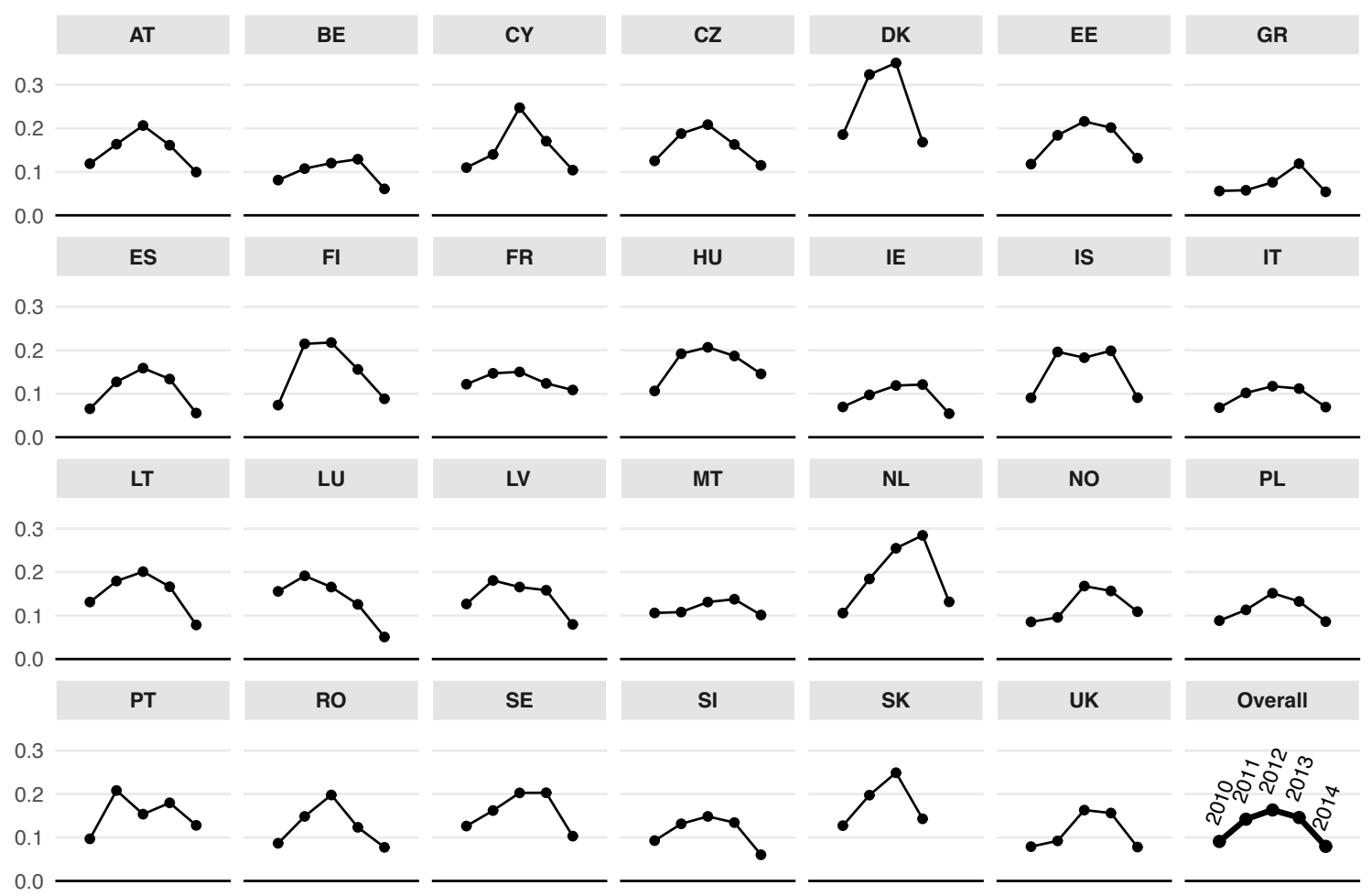

Figure 3: Transition probabilities from unemployment to any labour market segment by country 


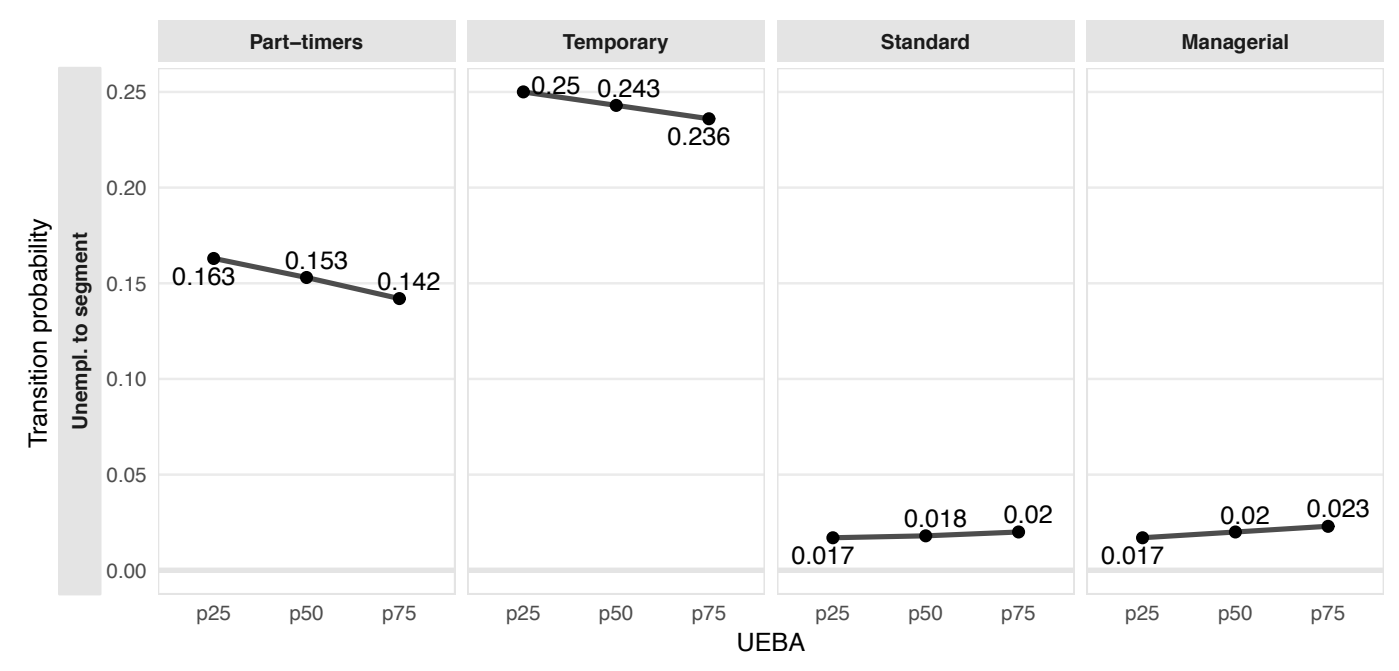

Figure 4: The effect of unemployment benefit amount rates on transition probabilities

contexts with relatively low benefits. Initially being in contrast to this expectation, the results of our analysis (Figure 4) show that in contexts with high relative unemployment benefit amounts transition probabilities for an unemployed to move into part-time or temporary employment decrease. However, at the same time we see support for the job-search subsidy hypothesis as the transition probabilities into standard and managerial work increase. For example, in contexts with low relative benefit amounts, the transition probability from unemployment to a position in the managerial labour market segment is predicted to be $1.7 \%$. In contexts with median and high benefit amount rates, the model estimates it to respectively $2 \%$ and $2.3 \%$. Transition probabilities for moving from unemployment into the standard employment segment also increase with the relative amount of unemployment benefits. The effects are significant but small, which is presumably because transition probabilities into the standard and managerial segment were initially much lower than the ones of temporary and part-time work. Moreover, since the reported estimates are the predicted transition probabilities at the 25 th percentile, the median, and the 75 th percentile value of our unemployment benefit amount rate variable, we actually report more modest effect sizes than minimum and maximum values of the distribution would have suggested. With regard to the two other segments, the transition probability for part-time work is predicted to decrease from $16.3 \%$ to $14.2 \%$ and the probability of moving from unemployment into temporary work is estimated to decrease from $25 \%$ to $23.5 \%$.

The results suggest two interpretations: First, higher benefits increase the reservation wage to accept less secure employment whilst, second, delivering a financial buffer for job search and skills development to find employment in more-secure positions. When comparing transition probabilities into the two less secure labour market segments, higher benefits appear to disincentivise transition into part-time employment more than into temporary employment.

Our third research question asks whether more-generous cash benefits alone promote the transition into specific labour market segments or if this also depends on ALMP. To this purpose, we include an interaction term in our model. The results in Figure 5 suggest that in contexts with high training-related ALMP spending, high unemployment benefits do indeed promote the transition from unemployment into more-secure work whilst this is not necessarily 


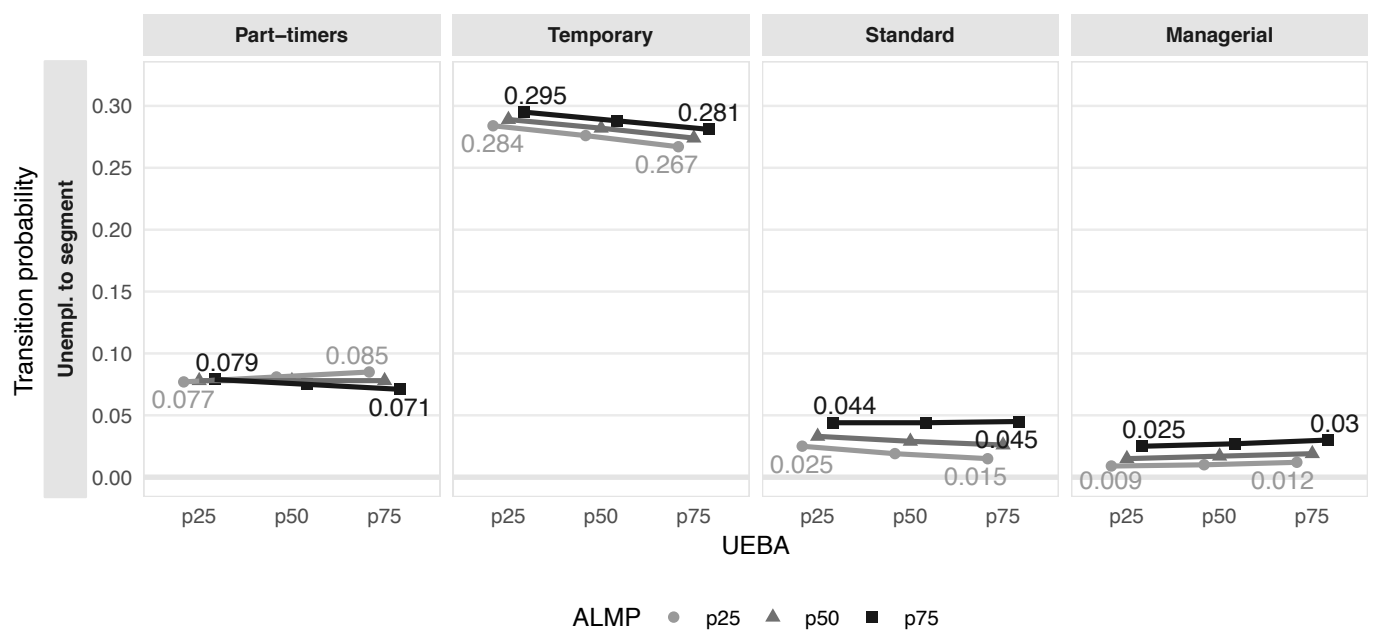

Figure 5: The effect of unemployment benefit amount rates and active labour market policy spending on transition probabilities

the case in contexts with low ALMP spending. For example, where ALMP spending on training and unemployment benefits are high, the probability of moving from unemployment into standard employment slightly increases from $1.5 \%$ to $4.5 \%$ and the probability of moving into managerial work grows from $1.2 \%$ to $3.0 \%$. For the transition into the managerial labour market segment, this positive effect of higher benefits also holds where ALMP spending is low. By contrast, the transition from unemployment into standard employment is clearly not helped by higher benefit amounts where they are not accompanied by high levels of trainingrelated ALMP spending. Altogether, this suggests that the job-search subsidy function of higher benefits works particularly well for transitions into these more-advantageous segments when combined with more or better training opportunities.

With regard to the insecure labour market segments, we find - comparable to the previous results - that higher unemployment benefit amounts disincentivise transition into part-time work and temporary jobs. The only exception are part-time jobs in contexts with low ALMP spending. Here, higher benefits are predicted to promote the transition from unemployment into this insecure labour market segment. Since we add GDP per capita as a covariate, we can to some extent rule out that the findings are a reflection of economic cycles. This means, decreasing transitions should not be the result of employers being discouraged from permanent hiring due to economic uncertainty.

\section{Conclusions and discussion}

Existing research is divided as to whether generous social benefits promote or disincentivise transition from unemployment to work. We claim that some of the inconclusiveness with which this question has been addressed is because most studies underestimate the segmentation of modern labour markets. This risks to neglect the possibility of a dialectical effect of generous benefits, whereby they promote transition into a particular type of work and discourage it into other types.

To close this knowledge gap, we investigated the following three research questions: (1.) What 
are the transition probabilities from unemployment into particular labour market segments in Europe and how do transition probabilities compare across countries? (2.) How does the generosity of unemployment benefits influence transition probabilities into particular labour market segments? and (3.) Do cash benefits alone help the transition into specific labour market segments or does this also depend on ALMP.

Contrary to most existing research into the employment effect of generous benefits, we do not assume a homogeneous labour market or pre-defined labour market segments. Instead, we follow earlier suggestions (Doerflinger et al., 2019) about insecurity as a dividing characteristic of modern labour markets to estimate segments by means of multilevel latent Markov models. This helped identify four theory-based but empirically modelled labour market segments: managerial, standard, temporary, and part-time work, in addition to the group of unemployed. The first two segments are considered more secure than the two latter ones.

Concerning to the first research question, our results showed that the probability of moving from unemployment into part-time and temporary work is much higher than the probability of moving from unemployment into standard or managerial work. Transitions from unemployment into standard and managerial work are, by contrast, less likely because employment protection rules might make it harder to get into them and - once in - to leave them. This is also what the probabilities for transition from the different segments into unemployment demonstrate. In line with what secure employment suggests, individuals in standard and managerial work face a much smaller risk of becoming unemployed than part-time and temporary workers. Further, we found that the transition probability for moving from unemployment into any of the labour market segments generally varies over time rather than across countries. More specifically, because of the negative employment effect of the Great Recession $2008 / 2009$, we observed a trend whereby in many European countries transition probabilities increased before going down again.

In addressing our second research question, we included the relative unemployment benefit amount as a country-level characteristic into our model. The results demonstrated that in contexts with high relative unemployment benefit amounts, transition probabilities for an unemployed to move into part-time or temporary employment decrease. This seems to support the earlier-mentioned work disincentive theory. However, at the same time we find support for the job-search subsidy hypothesis because the transition probabilities into standard and managerial work increase. The findings indicate that the employment effect of generous benefits does indeed vary between labour market segments and that they work particularly well for making the transition into secure work. Inspired by the argument of Gangl (2004, 2006), our interpretation of this finding is that in countries with higher relative unemployment benefit amounts, individuals use these partially decommodifying benefits as a financial buffer to look or prepare for more-secure jobs in the standard and managerial labour market segment instead of being forced to accept any job offer. Policy-wise, this implies that guaranteeing access to generous unemployment benefit rights can play a decisive role in the transition to more-secure labour market segments, especially for individuals from less-secure segments.

To investigate whether our findings depend on other influential policies - thus responding to our third research question - we included an interaction term for training-related ALMP spending. The results suggest that it is especially in contexts with high training-related ALMP spending that high unemployment benefits positively affect the transition from unemployment into secure work. This is not necessarily the case in contexts with low ALMP spending. The finding stresses that generous benefits alone might not do the job but that, in 
order to help people make the transition from unemployment into more-secure employment, a combination of both generous benefits and training opportunities is necessary. Comparable to recently published research (Dengler, 2019) that stresses the positive effect of trainingrelated ALMP on employment and/or work quality outcomes of benefit receiving jobseekers, our results revealed that higher levels of training-related ALMP spending generally increase the probability of moving from unemployment into temporary, standard or managerial work.

Nevertheless, even the most generous unemployment benefit and the best training opportunities might not promote employment where labour markets are not dynamic, sufficient job offers are missing or where key labour market institutions limit the availability of vacancies. Unfortunately, we were not able to consider this idea. As data on, for example, unionisation and employment protection rules is only available for a limited sample of countries, we could not test whether our findings also hold in contexts with a high degree of unionisation and a strong employment protection legislation - two aspects which were found to protect insiders and to limit labour market prospects for workers losing their jobs (Biegert, 2014, 2017; DiPrete et al., 2001; Gangl, 2006). However, their effect should to some extent be captured by the country-level random effects.

Additionally, several other knowledge gaps remain for future research. Since household-level characteristics can play an important role in individuals' probability of moving from unemployment into the labour market (Lehwess-Litzmann \& Nicaise, 2020), it could also be interesting to use household-level information in future research. This namely concerns the work intensity and the income of partners as well as the presence of small children in the household. Finally, we suggest more research into aspects that we could not take into account for reasons of data limitations in the EU-SILC. This mainly concerns the estimation of relative net instead of gross benefit amounts and the employment effect of benefits that are paid for a longer duration on the transition from unemployment into a segmented labour market. Following Atkinson and Micklewright (1991), benefit duration might be as, if not more, important for individuals' search behaviour than benefit levels. However, and despite these different limitations, we find our research to add more nuance and new insights to the ongoing discussion about the employment effect of generous social cash benefits. 


\section{References}

Acemoglu, D. (2001). Good jobs versus bad jobs. Journal of Labor Economics, 19(1), 1-21. https://doi.org/10.1086/209978

Addison, J. T., \& Blackburn, M. L. (2000). The effects of unemployment insurance on postunemployment earnings. Labour Economics, 7(1), 21-53. https://doi.org/10.1016/ s0927-5371(99)00026-3

Atkinson, A. B., \& Micklewright, J. (1991). Unemployment compensation and labor market transitions: A critical review. Journal of Economic Literature, 29(4), 1679-1727. http: //www.jstor.org/stable/2727794

Barbanchon, T. L. (2016). The effect of the potential duration of unemployment benefits on unemployment exits to work and match quality in France. Labour Economics, 42, 1629. https://doi.org/10.1016/j.labeco.2016.06.003

Bassanini, A., \& Duval, R. (2006). Employment Patterns in OECD Countries: Reassessing the Role of Policies and Institutions (OECD Economics Department Working Papers No. 486). OECD Publishing. https://doi.org/10.1787/846627332717

Baum, L. E., Petrie, T., Soules, G., \& Weiss, N. (1970). A Maximization Technique Occurring in the Statistical Analysis of Probabilistic Functions of Markov Chains. The Annals of Mathematical Statistics, 41(1), 164-171. https://doi.org/10.1214/aoms/1177697196

Bernardi, F. (2001). Is it a Timing or a Probability Effect? Four Simulations and an Application of Transition Rate Models to the Analysis of Unemployment Exit. Quality and Quantity, 35(3), 231-252. https://doi.org/10.1023/a:1010377327277

Beynon, H., Grimshaw, D., Rubery, J., \& Ward, K. (2002). Managing employment change: The new realities of work. Oxford University Press.

Biegert, T. (2014). On the outside looking in? Transitions out of non-employment in the United Kingdom and Germany. Journal of European Social Policy, 24(1), 3-18. https: //doi.org/10.1177/0958928713511283

Biegert, T. (2017). Welfare benefits and unemployment in affluent democracies: The moderating role of the institutional insider/outsider divide. American Sociological Review, 82(5), 1037-1064. https://doi.org/10.1177/0003122417727095

Bonoli, G., \& Natali, D. (2012). The politics of the new welfare state. Oxford University Press.

Bruckmeier, K., Eggs, J., Himsel, C., Trappmann, M., \& Walwei, U. (2013). Aufstocker im SGB II. Steinig und lang - der Weg aus dem Leistungsbezug (IAB-Kurzbericht). Institut für Arbeitsmarkt und Berufsforschung (IAB). http://doku.iab.de/kurzber/2013/ kb1413.pdf

Burdett, K. (1979). Unemployment insurance payments as a search subsidy: A theoretical analysis. Economic Inquiry, 17(3), 333-343. https://doi.org/10.1111/j.1465-7295. 1979.tb00533.x

Card, D., Johnston, A., Leung, P., Mas, A., \& Pei, Z. (2015). The Effect of Unemployment Benefits on the Duration of Unemployment Insurance Receipt: New Evidence from a Regression Kink Design in Missouri, 2003-2013. American Economic Review, 105(5), 126-30. https://doi.org/10.1257/aer.p20151061

Chung, H., \& Mau, S. (2014). Subjective insecurity and the role of institutions. Journal of European Social Policy, 24(4), 303-318. https://doi.org/10.1177/0958928714538214

Clasen, J., \& Clegg, D. (2011). Regulating the risk of unemployment: National adaptations to post-industrial labour markets in Europe. Oxford University Press. 
Collins, L., \& Lanza, S. (2010). Latent class and latent transition analysis: With applications in the social behavioral, and health sciences. Wiley.

Davidsson, J., \& Naczyk, M. (2009). The ins and outs of dualisation: A literature review. SSRN Electronic Journal. https://doi.org/10.2139/ssrn.1489906

De Deken, J., \& Clasen, J. (2011). Tracking caseloads: the changing composition of workingage benefit receipt in Europe. In J. De Deken \& J. Clasen (Eds.), Regulating the Risk of Unemployment: National Adaptations to Post-Industrial Labour Markets in Europe (pp. 297-317). Oxford University Press.

De Deken, J., \& Clasen, J. (2013). Benefit dependency: The pros and cons of using "caseload" data for national and international comparisons. International Social Security Review, 66(2), 53-78. https://doi.org/10.1111/issr.12009

Dengler, K. (2019). Effectiveness of Active Labour Market Programmes on the Job Quality of Welfare Recipients in Germany. Journal of Social Policy, 48(4), 807-838. https: //doi.org/10.1017/s0047279419000114

DiPrete, T. A., Goux, D., Maurin, E., \& Tåblin, M. (2001). Institutional Determinants of Employment Chances. The Structure of Unemployment in France and Sweden. European Sociological Review, 17(3), 233-254. https://doi.org/10.1093/esr/17.3.233

Doerflinger, N., Pulignano, V., \& Lukac, M. (2019). The social configuration of labour market divides: An analysis of Germany, Belgium and Italy. European Journal of Industrial Relations, 095968011986150. https://doi.org/10.1177/0959680119861505

Doeringer, P., \& Piore, M. J. (1971). Internal labor markets and manpower analysis. M.E. Sharpe.

Eichhorst, W., Kaufmann, O., \& Konle-Seidl, R. (2008). Bringing the jobless into work?: experiences with activation schemes in Europe and the US. Springer.

Emmenegger, P., Häusermann, S., Palier, B., \& Seeleib-Kaiser, M. (2012). The age of dualization: The changing face of inequality in deindustrializing societies. Oxford University Press.

Fernández-Macías, E. (2012). Job Polarization in Europe? Changes in the Employment Structure and Job Quality, 1995-2007. Work and Occupations, 39(2), 157-182. https://doi. org $/ 10.1177 / 0730888411427078$

Fourage, D., \& Muffels, R. (2008). Part-time Work and Childbirth in Europe: Scarring the Career or Meeting Working-time Perferences. In R. Muffels (Ed.), Flexibility and employment secruity in europe (pp. 223-254). Edward Elgar Publishing.

Gangl, M. (2004). American Journal of Sociology, 109(6), 1319-1364.

Gangl, M. (2006). Scar effects of unemployment: An assessment of institutional complementarities. American Sociological Review, 71(6), 986-1013.

Goldthorpe, J. (1984). The end of convergence: Corporatist and dualist tendencies in modern western societies. Order and conflict in contemporary capitalism (pp. 315-344). Clarendon Press.

Goodman, L. A. (1974). Exploratory latent structure analysis using both identifiable and unidentifiable models. Biometrika, 61 (2), 215-231. https://doi.org/10.1093/biomet/ 61.2 .215

Green, F. (2009). Subjective employment insecurity around the world. Cambridge Journal of Regions, Economy and Society, 2(3), 343-363. https://doi.org/10.1093/cjres/rsp003

Greenhalgh, L., \& Rosenblatt, Z. (1984). Job insecurity: Toward conceptual clarity. The Academy of Management Review, 9(3), 438-448. 
Grimshaw, D., Cartwright, J., Keizer, A., \& Rubery, J. (2018). Market exposure and the labour process: The contradictory dynamics in managing subcontracted services work. Work, Employment and Society, 33(1), 76-95. https://doi.org/10.1177/0950017018759206

Hagenaars, J., \& McCutcheon, A. (2002). Applied latent class analysis. Cambridge University Press.

Hassel, A. (2001). The governance of the employment-welfare relationship in Britain and Germany. In B. Ebbinghaus \& P. Manow (Eds.), Comparing welfare capitalism: social policy and political economy in Europe, Japan and the USA (pp. 146-168). Routledge.

Hipp, L., Bernhardt, J., \& Allmendinger, J. (2015). Institutions and the prevalence of nonstandard employment. Socio-Economic Review, 13(2), 351-377. https://doi.org/10. 1093/ser/mwv002

Horemans, J. (2017). Atypical employment and in-work poverty. Leuven, KU Leuven, IPSWICH working paper No. 1.

Howell, D. R., \& Rehm, M. (2009). Unemployment compensation and high European unemployment: a reassessment with new benefit indicators. Oxford Review of Economic Policy, 25(1), 60-93. https://doi.org/10.1093/oxrep/grp010

International Labour Organisation. (2017). Women in non-standard employment (INWORK Issue Brief No. 9). OECD. Geneva.

Kalleberg, A. L. (2003). Flexible firms and labor market segmentation. Work and Occupations, 30 (2), 154-175. https://doi.org/10.1177/0730888403251683

Kalleberg, A. L., Reskin, B. F., \& Hudson, K. (2000). Bad Jobs in America: Standard and Nonstandard Employment Relations and Job Quality in the United States. American Sociological Review, 65(2), 256-278.

Kankaraš, M., Moors, G., \& Vermunt, J. (2010). Testing for measurement invariance with latent class analysis. In E. Davidov, P. Schmidt, \& J. Billiet (Eds.), Cross-cultural analysis: Methods and applications (pp. 359-384). Routledge.

Knotz, C. M. (2018). A rising workfare state? Unemployment benefit conditionality in 21 OECD countries, 1980-2012. Journal of International and Comparative Social Policy, 34 (2), 91-108. https://doi.org/10.1080/21699763.2018.1472136

Kunißen, K. (2018). From dependent to independent variable: A critical assessment of operationalisations of 'welfare stateness' as macro-level indicators in multilevel analyses. Social Indicators Research, 142(2), 597-616. https://doi.org/10.1007/s11205-0181930-3

Lalive, R. (2007). Unemployment benefits, unemployment duration, and post-unemployment jobs: A regression discontinuity approach. American Economic Review, 97(2), 108112. https://doi.org/10.1257/aer.97.2.108

Langeheine, R., \& van de Pol, F. (1990). A unifying framework for markov modeling in discrete space and discrete time. Sociological Methods \& Research, 18(4), 416-441. https://doi.org/10.1177/0049124190018004002

Langenbucher, K. (2015). How demanding are eligibility criteria for unemployment benefits, quantitative indicators for OECD and EU countries (OECD Social, Employment and Migration Working Papers No. 166). OECD. Paris.

Layard, R., Nickell, S., \& Jackman, R. (2005). Unemployment: Macroeconomic performance and the labour market. Oxford University Press. https://doi.org/10.1093/acprof: oso/9780199279166.001.0001 
Lehwess-Litzmann, R., \& Nicaise, I. (2020). Surprisingly small: Effects of "generous" social benefits on re-employment of (quasi-) jobless households. Journal of International and Comparative Social Policy, 36(1), 76-91. https://doi.org/10.1017/ics.2020.1

Leisering, L., \& Leibfried, S. (1999). Time and poverty in western welfare states: United Germany in perspective. Cambridge University Press.

Leschke, J., \& Jepsen, M. (2011). Can transitional labour markets contribute to a less traditional gender division of labour? Journal of Economic and Social Policy, 14(1), 124151.

Lukac, M., Doerflinger, N., \& Pulignano, V. (2019). Developing a cross-national comparative framework for studying labour market segmentation: Measurement equivalence with latent class analysis. Social Indicators Research, 145(1), 233-255. https://doi.org/10. 1007/s11205-019-02101-3

MacDonald, I. L., \& Zucchini, W. (1997). Hidden markov and other models for discrete-valued time series. Chapman \& Hall.

McCall, J. J. (1970). Economics of information and job search. The Quarterly Journal of Economics, 84(1), 113. https://doi.org/10.2307/1879403

Meyer, B. D. (1990). Unemployment insurance and unemployment spells. Econometrica, 58(4), 757-782.

Morel, N., Palier, B., \& Palme, J. (2012). Towards a social investment welfare state? Ideas, policies and challenges. Policy Press.

Mortensen, D. T. (2001). A theory of wage and employment dynamics. In E. S. Phelps (Ed.), Microeconomic foundations of employment and inflation theory (pp. 167-211). W. W. Norton.

Nelson, M., \& Stephens, J. D. (2012). Do social investment policies produce more and better jobs? In N. Morel, B. Palier, \& J. Palme (Eds.), Towards a Social Investment Welfare State? Ideas, Policies and Challenges (pp. 205-234). Policy Press.

Nickell, S. (1997). Unemployment and Labor Market Rigidities: Europe versus North America. Journal of Economic Perspectives, 11(3), 55-74. https://doi.org/10.1257/jep.11.3.55

Nilsen, Ø. A., \& Reiso, K. H. (2011). Scarring effects of unemployment (IZA Discussion Paper No. 6198). Institute for the Study of Labor (IZA). http://ftp.iza.org/dp6198.pdf

Nylund, K. L., Asparouhov, T., \& Muthén, B. O. (2007). Deciding on the Number of Classes in Latent Class Analysis and Growth Mixture Modeling: A Monte Carlo Simulation Study. Structural Equation Modeling: A Multidisciplinary Journal, 14(4), 535-569. https://doi.org/10.1080/10705510701575396

Otto, A. (2018). A Benefit Recipiency Approach to Analysing Differences and Similarities in European Welfare Provision. Social Indicators Research, 137(2), 765-788. https: //doi.org/10.1007/s11205-017-1621-5

Otto, A., \& van Oorschot, W. (2018). Welfare reform by stealth? Cash benefit recipiency data and its additional value to the understanding of welfare state change in Europe. Journal of European Social Policy, 29(3), 307-324. https://doi.org/10.1177/ 0958928718796299

Palier, B., \& Thelen, K. (2010). Institutionalizing dualism: Complementarities and change in france and germany. Politics \& Society, 38(1), 119-148. https://doi.org/10.1177/ 0032329209357888

Paugam, S. (1995). The spiral of precariousness: A multidimensional approach to the process of social disqualification in france. In G. Room (Ed.), Beyond the threshold: The measurement and analysis of social exclusion (pp. 47-79). Policy Press. 
Piore, M. J. (1972). Notes for a theory of labor market stratification (No. 95). MIT, working paper of the Department of Economics.

Pollmann-Schult, M., \& Büchel, F. (2005). Unemployment Benefits, Unemployment Duration and Subsequent Job Quality: Evidence from West Germany. Acta Sociologica, 48(1), 21-39. https://doi.org/10.1177/0001699305050985

Portugal, P., \& Addison, J. T. (2008). Six ways to leave unemployment. Scottish Journal of Political Economy, 55(4), 393-419. https://doi.org/10.1111/j.1467-9485.2008.00459.x

Rodgers, G. (1989). Precarious work in Western Europe: The state of the debate. In G. Rodgers \& J. Rodgers (Eds.), Precarious Jobs in Labour Market Regulation: The Growth of Atypical Employment in Western Europe. International Labour Organization, International Institute for Labour Studies.

Rubery, J. (1978). Structured labour markets, worker organisation and low pay. Cambridge Journal of Economics, 2(1), 17-36.

Sjöberg, O. (2000). Unemployment and Unemployment Benefits in the OECD 1960-1990 An Empirical Test of Neo-Classical Economic Theory. Work, Employment and Society, 14(1), 51-76. https://doi.org/10.1177/09500170022118266

Sverke, M., Hellgren, J., \& Näswall, K. (2006). Arbeitsplatzunsicherheit: Überblick über den Forschungsstand. In B. Badura, H. Schnellschmidt, \& C. Vetter (Eds.), Fehlzeitenreport 2005. arbeitsplatzunsicherheit und gesundheit (pp. 59-92). Springer Verlag.

Tatsiramos, K. (2009). Unemployment insurance in Europe: unemployment duration and subsequent employment stability. Journal of the European Economic Association, 7(6), $1225-1260$.

Taylor-Gooby, P., Gumy, J. M., \& Otto, A. (2014). Can 'new welfare' address poverty through more and better jobs? Journal of Social Policy, 44(1), 83-104. https://doi.org/10. $1017 / \mathrm{s} 0047279414000403$

Uusitalo, R., \& Verho, J. (2010). The effect of unemployment benefits on re-employment rates: Evidence from the finnish unemployment insurance reform. Labour Economics, 17(4), 643-654. https://doi.org/10.1016/j.labeco.2010.02.002

van Oorschot, W. (2013). Comparative Welfare State Analysis with Survey-Based Benefit: Recipiency Data: The 'Dependent Variable Problem' Revisited. European Journal of Social Security, 15(3), 224-248. https://doi.org/10.1177/138826271301500301

Vermunt, J. (2010a). Latent class modeling with covariates: Two improved three-step approaches. Political Analysis, 18(4), 450-469. https://doi.org/10.1093/pan/mpq025

Vermunt, J. (2010b). Longitudinal research using mixture models. In K. van Montfort, J. H. Oud, \& A. Satorra (Eds.), Longitudinal research with latent variables (pp. 119-152). Springer Berlin Heidelberg. https://doi.org/10.1007/978-3-642-11760-2_4

Vermunt, J., Tran, B., \& Magidson, J. (2008). Latent class models in longitudinal research. In S. W. Menard (Ed.), Handbook of longitudinal research: Design, measurement, and analysis (pp. 373-385). Elsevier.

Wulfgramm, M., \& Fervers, L. (2015). Unemployment and subsequent employment stability: Does labour market policy matter? Socio-Economic Review, 13(4), 791-812. https: //doi.org/10.1093/ser/mwv020

Yoon, Y., \& Chung, H. (2015). New Forms of Dualization? Labour Market Segmentation Patterns in the UK from the Late 90s Until the Post-crisis in the Late 2000s. Social Indicators Research, 128(2), 609-631. https://doi.org/10.1007/s11205-015-1046-y 
Technical appendix: Multilevel latent Markov model The dataset contains responses on multiple variables for individuals nested within countries over multiple time-points. Let $y_{i g t j}$ denote the response of subject $i$ within country $g$ at occasion $t$ on response variable $j$, where $1 \leq i \leq N, 1 \leq g \leq G, 1 \leq t \leq T_{i}$, and $1 \leq j \leq J$. The vector collecting all responses of subject $i$ is denoted as $\mathbf{y}_{\mathbf{i}}$. The model contains a time-varying discrete latent variable (referred to as latent state) that is denoted by $x_{i t}$ with $K$ categories (specific categories being indexed as $k_{t}$ ), that is $1 \leq x_{i t}=k_{t} \leq K$. The vector of time-varying covariates at occasion $t$ is denoted as $\mathbf{z}_{\mathbf{i t}}$ (i.e. gender, education, and age). Finally, a country-level time-varying predictor of benefit amount rate is denoted as $B_{g t}$. The latent Markov model can be defined as follows (Vermunt, 2010b):

$$
\begin{aligned}
P\left(\mathbf{y}_{\mathbf{i}}\right) & =\sum_{k_{0}=1}^{K} \sum_{k_{1}=1}^{K} \ldots \sum_{k_{T}=1}^{K} P\left(x_{i g 0}=k \mid \mathbf{z}_{\mathbf{i} \mathbf{0}}\right) \\
& \times\left[\prod_{t=1}^{T} P\left(x_{i g t}=k \mid x_{i g(t-1)}=k_{t-1}, B_{g t}\right)\right] \\
& \times\left[\prod_{t=0}^{T_{i}} \prod_{j=1}^{J} P\left(y_{i g t j} \mid x_{i t}=k_{t}\right)\right]
\end{aligned}
$$

and contains three different kinds of model probabilities: First, $P\left(x_{i g 0}=k \mid \mathbf{z}_{\mathbf{i 0}}\right)$ denotes an initial-state probability of having a particular latent state at $t=0$ for individual $i$ in country $g$, conditional on covariates $\mathbf{z}_{\mathbf{i} \mathbf{0}}$. In our case, this is the probability of being in a labour market segment $k$ at the first observed occasion, conditional on observed covariates.

Second, $P\left(x_{i g t}=k \mid x_{i g(t-1)}=k_{t-1}, B_{g t}\right)$ is a latent transition probability; that is, the probability of being in a latent state $k$ at time $t$, conditional on the latent state in the previous time point $k_{t-1}$ and the country-level variable of benefit amount rate $\left(B_{g t}\right)$.

Finally, $P\left(y_{i g t j} \mid x_{i t}=k_{t}\right)$ denotes the latent state profile; that is a response probability density of having a particular observed value for individual $i$ in country $g$ on response variable $j$ at time point $t$, conditional on latent state occupied at $t$. In other words, responses to indicators of labour market segmentation (i.e. working hours, contract type, incidence of non-standard working schedules, managerial responsibility, and wage income) are dependent on the labour market segment that an individual occupies at that specific time point.

Typically, these sets of probabilities are parametrized and restricted by means of regression models from the generalized linear modelling family:

$$
P\left(x_{i g 0}=k \mid \mathbf{z}_{\mathbf{i 0}}\right)=\frac{e^{\alpha_{0 k}^{0}+\sum_{q=1}^{Q} \alpha_{0 q k}^{0} z_{i 0 q k}+\tau_{0 g}^{0} u_{0 g}^{0}}}{\sum_{k^{\prime}=1}^{K} e^{\alpha_{0 k^{\prime}}^{0}+\sum_{q=1}^{Q} \alpha_{0 q k^{\prime}}^{0} z_{i 0 q k^{\prime}}+\tau_{0 g}^{0} u_{0 g}^{0}}}
$$

The initial-state probability is parametrized in Eq. 3.2. The term $\alpha_{0 k}^{0}$ denotes a logistic parameter that differentiates the baseline probability of being in latent state $k$ at $t_{0}$. The second term, $\sum_{q=1}^{Q} \alpha_{0 q k}^{0} z_{i 0 q k}$ loops over all covariates and shows how is the initial probability of being in latent state $k$ is influenced by covariates. Finally, $\tau_{0 g}^{0} u_{0 g}^{0}$ denotes a country random effect, influencing the baseline probability of being in latent state $k$ depending on the country $g$. 


$$
\begin{aligned}
& P\left(x_{i g t}=k \mid x_{i g(t-1)}=k_{t-1}, B_{g t}\right)=\frac{e^{\alpha_{0 n k}+\alpha_{1 n k} B_{g t}+\tau_{g n k} u_{g n k}}}{\sum_{k^{\prime}=1}^{K} e^{\alpha_{0 n k^{\prime}}+\alpha_{1 n k^{\prime}} B_{g t}+\tau_{g n k^{\prime}} u_{g n k^{\prime}}}} \\
& P\left(x_{i g t}=k \mid x_{i g(t-1)}=k_{t-1}=k_{t-1}, B_{g t}, A L M P_{g t}, G D P_{g t}\right)= \\
& \frac{e^{\alpha_{0 n k}+\alpha_{1 n k} B_{g t}+\alpha_{2 n k} A L M P_{g t}+\alpha_{3 n k} B_{g t} A L M P_{g t}+G D P_{g t}+\tau_{g n k} u_{g n k}}}{\sum_{k^{\prime}=1}^{K} e^{\alpha_{0 n k^{\prime}}+\alpha_{1 n k^{\prime}} B_{g t}+\alpha_{2 n k^{\prime}} A L M P_{g t}+\alpha_{3 n k^{\prime}} B_{g t} A L M P_{g t}+G D P_{g t}+\tau_{g n k^{\prime}} u_{g n k^{\prime}}}}
\end{aligned}
$$

The transition structure is parametrised in Eq. 3.3, with $\alpha_{0 n k}$ as a baseline parameter governing transitions between $k_{t-1}$ and $k_{t}$. Similar to standard multinomial logit model, identifying restrictions are placed by using transition coding proposed by Vermunt et al. (2008), where the coefficients are fixed to 0 for $k_{t}=k_{t-1}$. This implies that the free coefficients can be interpreted as effects on the logit of a transition from $k$ to $k^{\prime}$. Moreover, $\alpha_{1 n k}$ denotes the effect of $B_{g t}$ on the transitions between segments. This parameter is of crucial interest, as our hypothesis about the effect of benefit amount rate on transition probabilities is focused on this quantity.

Model shown in Eq. 3.4 is an extension of Eq. 3.3, with added interaction between $B_{g t}$ and $A L M P_{g t}$, and a direct effect of $G D P_{g t}$ on the transition probability. This extension is to answer the third research question, where we inquire about the interaction effect between benefit amount rate and active labour market policy spending. The parameter $\alpha_{3 n k}$ reflects this interaction. Moreover, we explicitly control for the effect of GDP to ensure that the results are not confounded by the effect of the Great Recession. Finally, $\tau_{g n k} u_{g n k}$ denotes a country random effect, which allows countries to differ in segment-to-segment transition probabilities.

$$
P\left(y_{i g t j} \mid x_{i t}=k_{t}\right)=\frac{e^{\left.\alpha_{1 j}+\alpha_{1 j k}+\tau_{j k g} u_{j k g}\right)}}{\sum_{k^{\prime}=1}^{K} e^{\left.\alpha_{1 j}+\alpha_{1 j k^{\prime}}+\tau_{j k^{\prime} g} u_{j k^{\prime} g}\right)}}
$$

Finally, response probability density (or latent profile) is parametrised in Eq. 3.5. Parameter $\alpha_{1 j k}$ denotes the baseline response probability for indicator $j$. This baseline probability is adjusted by depending on the individual's membership in a latent state $k$. This term is defining the conceptual connection between the observed indicator and the latent variable that is modelled. In our case, for example, $\alpha_{1 j k}$ could denote a change in probability of having a temporary contract (vs. a permanent contract), given that an individual is in an insecure labour market segment. Finally, $\tau_{j k g} u_{j k g}$ denotes a country random effect, that allows countries to differ in their baseline probability across all response indicators (Kankaraš et al., 2010; Lukac et al., 2019).

The proposed model makes some additional assumptions about the modelling process that need to be made explicit. First, the country-level random effects $(u$-terms) are assumed to be distributed as $\operatorname{Normal}\left(\mu=0, \sigma^{2}=1\right)$, which is a common assumption for multilevel modelling. It is also a simplifying assumption, since using non-parametric random effects would substantially complicate the model and create additional complexity in model estimation. Second, often called the Markov assumption, the model assumes that conditional on covariates $\mathbf{z}_{\mathbf{i}}, x_{i t}$ is associated only with its previous $\left(x_{i(t-1)}\right)$ and future $\left(x_{i(t+1)}\right)$ time-points. Potentially, this assumption can be relaxed by adding associations also with more distant time-points $(t-2$ and $t+2)$. However, as we have only a maximum of four consecutive observations for each individual, this would make our estimates of the transitions less stable and also substantially increase the number of free parameters in the model. We therefore decided to proceed with the first-order Markov assumption. Finally, we assume that conditionally on $x_{i t}$ and $\mathbf{z}_{\mathbf{i t}}$, the 
$J$ responses on occasion $t$ are independent of the latent states and the responses at other time points, and that $J$ responses are also mutually independent. This assumption is known as the local independence assumption (Goodman, 1974) and is commonly made with latent class analysis. 


\section{Affiliation:}

Adeline Otto

Center for Sociological Research (CeSO)

KU Leuven

E-mail: adeline.otto@kuleuven.be

Martin Lukac

Department of Methodology

London School of Economics and Political Science

E-mail: m.lukac@lse.ac.uk

URL: http://mblukac.github.io

\section{SocArXiv Preprints}

Preprint

10.31235/osf.io/2xuqf https://osf.io/preprints/socarxiv

Submitted: March 11, 2021

Accepted: March 11, 2021 